\title{
Associations between successful palliative cancer pathways and community nurse involvement
}

\author{
Mette Asbjoern Neergaard*1,2, Peter Vedsted ${ }^{\dagger 2}$, Frede Olesen ${ }^{\dagger 2}$, \\ Ineta Sokolowski ${ }^{\dagger 2}$, Anders Bonde Jensen ${ }^{\dagger 3}$ and Jens Sondergaard ${ }^{\dagger 4}$
}

\begin{abstract}
Address: ${ }^{1}$ The Palliative Specialist Team, Department of Oncology, Aarhus University Hospital, Noerrebrogade, Aarhus, Denmark, ${ }^{2}$ The Research Unit for General Practice, University of Aarhus, Bartholin Allé, Aarhus, Denmark, 32Department of Oncology, Aarhus University Hospital, Randersvej, Aarhus, Denmark and ${ }^{4}$ The Research Unit and Department for General Practice, University of Southern Denmark, J.B. Winsløws Vej, Odense, Denmark

Email: Mette Asbjoern Neergaard* - man@alm.au.dk; Peter Vedsted - p.vedsted@alm.au.dk; Frede Olesen - fo@alm.au.dk; Ineta Sokolowski - ineta.s@alm.au.dk; Anders Bonde Jensen - andjense@rm.dk; Jens Sondergaard - JSoendergaard@health.sdu.dk

* Corresponding author †Equal contributors
\end{abstract}

Published: I4 December 2009

BMC Palliative Care 2009, 8:18 doi:10.1/86/1472-684X-8-18
Received: I March 2009

Accepted: 14 December 2009

This article is available from: http://www.biomedcentral.com/l472-684X/8//8

(c) 2009 Neergaard et al; licensee BioMed Central Ltd.

This is an Open Access article distributed under the terms of the Creative Commons Attribution License (http://creativecommons.org/licenses/by/2.0), which permits unrestricted use, distribution, and reproduction in any medium, provided the original work is properly cited.

\begin{abstract}
Background: Most terminally ill cancer patients and their relatives wish that the patient dies at home. Community nurses $(\mathrm{CNs})$ are often frontline workers in the patients' homes and $\mathrm{CN}$ involvement may be important in attaining successful palliative pathways at home.

The aim of the present study was to examine associations between bereaved relatives' evaluation of palliative treatment at home and I) place of death and 2) $\mathrm{CN}$ involvement.

Methods: The study is a population-based, cross-sectional combined register and questionnaire study performed in Aarhus County, Denmark. CN questionnaires were used to obtain data on $\mathrm{CNs}$ ' efforts, GP-questionnaires were used to obtain data on pathway characteristics and relatives answered questionnaires to evaluate the palliative pathway at home. Questionnaires addressed the palliative pathway of a total of 599 deceased cancer patients. Associations between bereaved relatives' evaluation of palliative pathways at home and place of death and $\mathrm{CN}$ involvement were analysed.
\end{abstract}

Results: 'A successful palliative pathway at home' was positively associated with home-death and death at a nursing home compared with death at an institution. No significant associations were identified between the evaluations of the palliative pathway at home and the involvement of CNs.

Conclusions: Our study indicates that dying at home is positively associated with a higher likelihood that the bereaved relative will evaluate the palliative pathway at home as successful. The absence of any significance of involvement of CNs may be ascribed to the variables for involvement chosen in the study. More research is needed on CNs' impact on palliative pathways.

\section{Background}

Most terminally ill cancer patients and their relatives wish that the patient be cared for and die at home [1-3] and home-death is therefore almost always the main outcome when evaluating end-of-life care. However, home-death is not necessarily tantamount to a successful palliative path- 
way at home, since many factors and the professionals involved can shape the patients' or the relatives' views. Furthermore, in a previous study we found that even though patients died at institutions (hospital and hospice), they spent three quarters of the time in the palliative pathway at home (mean, \% (95\% CI): 75.1 (71.0;79.1)) [4]. This makes it even more important to question homedeath as a measure of a successful palliative period at home, i.e. the last period of the patient's life during which all curative treatment had been discontinued and care and treatment were provided for palliative purposes only.

The community nurses (CNs) play an important role during the palliative period when the patient is at home, since $\mathrm{CNs}$ are frontline workers whether a specialist team or only the GP is involved. Previous studies suggest that 24hour back-up and overall involvement of the CNs is an important factor in bereaved relatives' evaluation of palliative pathways [5-7]. Furthermore, research has also shown that involvement of a $\mathrm{CN}$ is positively associated with home-death [4,8-10]. However, we lack sufficient knowledge of the importance of the CNs' personal data, skills and different services in relation to achieving a successful palliative pathway at home.

The aim of the present study was to examine the association between the bereaved relatives' evaluation of palliative pathways at home and 1) place of death and 2) CNs' involvement.

\section{Methods}

We conducted a population-based, cross-sectional combined register and questionnaire study. Questionnaires were filled in by relatives evaluating the palliative pathways, by CNs and by GPs. Questionnaires addressed the palliative pathways of a total of 599 deceased cancer patients (Figure 1).

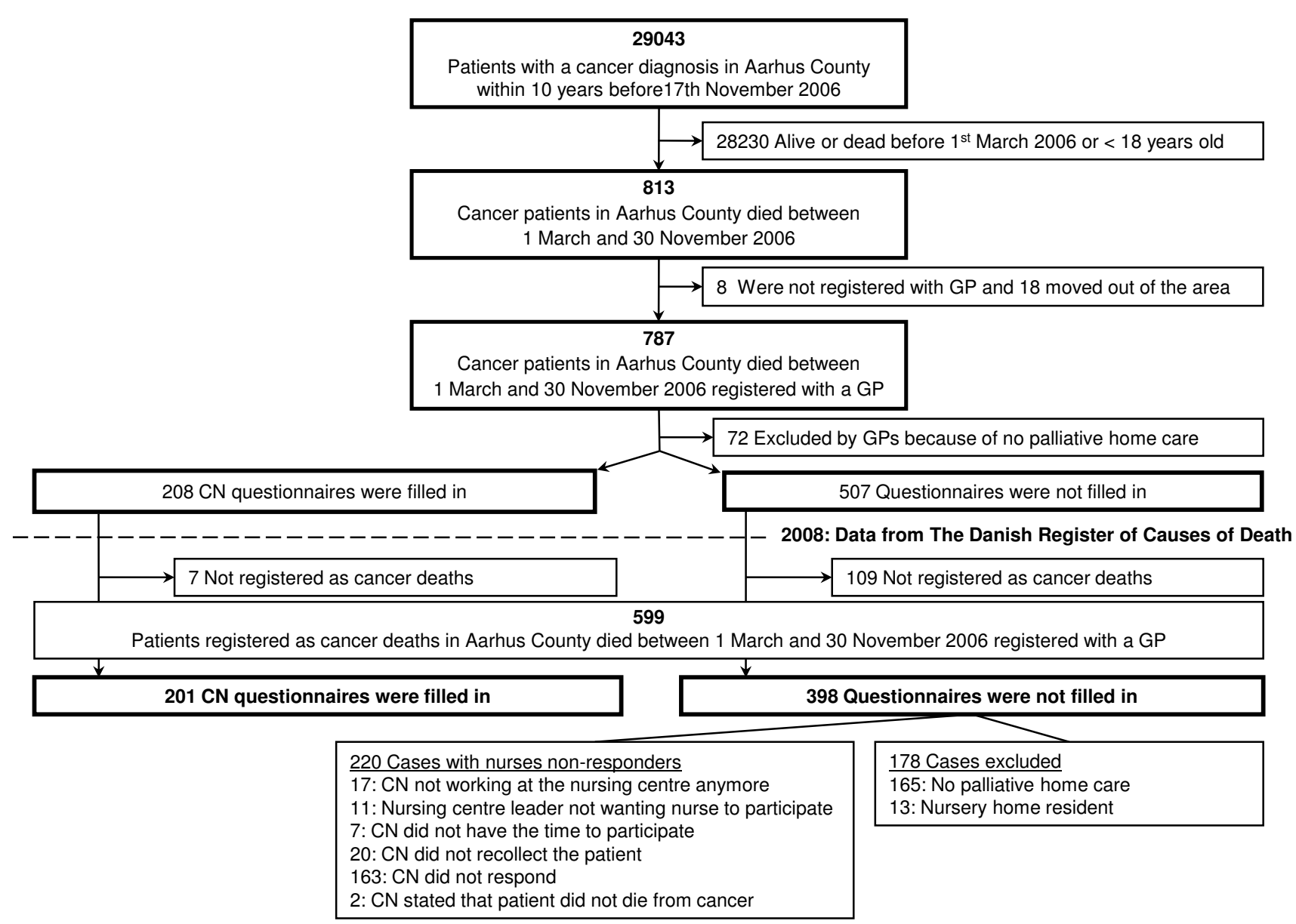

\section{Figure I}

Flow-chart of sampling of study population and data collection. Community nurses (CNs) questionnaires. Responders and non-responders. 


\section{Setting}

The Danish health care system is tax-financed and provides free care for those in need of help at home. Care is provided by GPs, CNs and home carers. CNs employed by the municipalities are most often involved in palliative pathways in the patient's home, especially in the terminal phase. They may visit patients on a 24-hour basis.

Denmark has no formal national agreement on task distribution in palliative care. Palliative specialist outgoing teams based at the major hospitals are available during daytime hours, and specialist advice can be obtained from these specialist teams by CNs or GPs by telephone.

The study took place in 2007 (January - July) in The Aarhus County, which at the time comprised approximately 640000 inhabitants, $12 \%$ of the Danish population, 43 municipalities. The annual cancer mortality amounted to 1680 persons in 2005 [11]. Numbers for 2006 are still not available.

In Denmark, all citizens are registered with unique civil registration numbers [12]. Questionnaire data were linked to health register information by means of these numbers.

\section{Study population and sampling}

Since no database on palliative patients is available in Denmark, we decided to focus on cancer patients since these patients are included in validated Danish registers. We sampled the patients by combining official register data with questionnaires information. The study included adults in Aarhus County who died from cancer from $1^{\text {st }}$ March to $30^{\text {th }}$ November 2006 and who had received some palliative home care either from CNs, GPs or a palliative specialist team.

From the county hospital discharge register, we identified 29,043 individuals above 18 years who were registered with at least one cancer diagnosis (ICD-10) (excluding non-melanoma skin cancers) during the period November 2006 and ten years back. In December 2006, using the Civil Registration System database, we identified 813 patients among the 29,042 who died from $1^{\text {st }}$ March to $30^{\text {th }}$ November 2006 (nine months). From the regional health authority's register, we identified their GPs. Eight $(1.0 \%)$ patients were not registered with a GP and 18 $(2.2 \%)$ had moved from the county after having been diagnosed, leaving 787 deceased cancer patients for analysis. A CN questionnaire was sent to the local health centre of the patient's address, and a GP questionnaire was sent to the patient's GP. They were asked about cause of death, if palliative care had been provided in the patient's home and if the closest bereaved relative could receive a questionnaire. If one of the two ( $\mathrm{CN}$ or GP) advised against sending the relative a questionnaire, it was not sent. The closest relative was defined by the professionals, but if they stated that we could contact the relative, but without providing the name or the address, we sent the questionnaire to relatives in the following order: spouse, child above 18 years, oldest sibling and parent (data from the Civil Registration System database). We asked the person contacted to give the questionnaire to the closest relative involved in the palliative pathway.

In late 2008, data from the Danish Register of Causes of Death for deaths in 2006 were available. Merging the information of cancer deaths with our database, we excluded 188 patients who were not registered with cancer as cause of death, which reduced our study population to 599 deceased cancer patients (Figure 1).

\section{Data collection}

The study comprises data from three mail-delivered questionnaires, one for CNs, one for GPs and one for relatives of deceased cancer patients. The questionnaires included themes identified through literature studies, clinical experience and group interview studies with bereaved relatives [5] and health professionals (CNs, GPs and hospital consultants). The themes in the questionnaires can be seen in Table 1. Only a small part of the data from the questionnaires was used in this study since it is part of a larger research project with present and future publications [13].

The 46-item CN questionnaire was pilot-tested among 14 CNs who had also participated in a prior interview study[5]. Data included information on the nurse's age ($39,40+)$, number of years as CN $(0-5,6+)$, amount of extra education or classes in palliative care (no, yes), knowledge of the patient before the palliative period (dichotomized into poor (1,2 on a 1-5-point scale) and good (3,4 and 5)), whether the nurse had contact to the patient's relatives (no/yes) and how often the nurse or community services paid the patient a home-visit (less than once a day, once a day or more). If the CNs did not respond, two reminders were sent four and seven weeks after the first questionnaire, respectively.

The 72-item GP questionnaire was pilot-tested among 30 GPs in another Danish county. In this study, GP questionnaires were mainly used to locate relatives and $\mathrm{CNs}$, to inform that a palliative pathway had taken place at home or not, and to determine the duration of the palliative period. Thus, data from the GP questionnaires included information on the involvement of a GP (no, yes) or a specialist team (no, yes) and the duration of the palliative period at home in weeks. The palliative period was defined as the last period of the patient's life during which all curative treatment had been discontinued and care and treatment were provided for palliative purposes only. GPs 
Table I: Themes in questionnaires

\begin{tabular}{|c|c|}
\hline CN questionnaire & Validation questions about the cause of death \\
\hline \multirow[t]{13}{*}{ (46-item questionnaire) } & Information about closest relative and the $\mathrm{CN} /$ centre involved. \\
\hline & CN knowledge of patient before the palliative pathway \\
\hline & Type of contact \\
\hline & Patient's wish for and actual place of death \\
\hline & Care for the relative during the palliative period and after bereavement \\
\hline & Cooperation with GPs, hospital doctors, palliative specialist team \\
\hline & When discharging the patient from the hospital \\
\hline & When the patient is at home \\
\hline & Evaluation the primary care sector's effort \\
\hline & Evaluation of CN's own effort \\
\hline & Overall view on palliative care in primary care \\
\hline & Demographic data of the CN \\
\hline & Open question on comments to the questionnaire \\
\hline GP questionnaire & Validation questions about the cause of death \\
\hline \multirow[t]{14}{*}{ (72-item questionnaire) } & Information about closest relative and the community nurse/centre involved. \\
\hline & GP knowledge of patient before the palliative pathway \\
\hline & Length of the palliative period \\
\hline & Type of contact \\
\hline & Patient's wish for and actual place of death \\
\hline & Care for the relative during the palliative period and after bereavement \\
\hline & Cooperation with CNs, hospital doctors, palliative specialist team \\
\hline & Especially when discharging the patient from the hospital \\
\hline & When the patient is at home \\
\hline & Evaluation the primary care sector's effort \\
\hline & Evaluation of GP's own effort \\
\hline & Overall view on palliative care in primary care \\
\hline & Demographic data of the GP's practice \\
\hline & Open question on comments to the questionnaire \\
\hline Questionnaire for bereaved relatives & Demographic data of deceased \\
\hline \multirow[t]{10}{*}{ (65-item questionnaire) } & Length of the palliative period \\
\hline & Type of contact to professionals \\
\hline & Patient's wish for and actual place of death \\
\hline & Care for the relative during the palliative period and after bereavement \\
\hline & Cooperation among GPs, CNs, hospital doctors, palliative specialist team \\
\hline & When discharging the patient from the hospital \\
\hline & When the patient is at home \\
\hline & Evaluation the primary care sector's effort \\
\hline & Demographic data of the relative \\
\hline & Open question on comments to the questionnaire \\
\hline
\end{tabular}

received a small economic compensation for their efforts since the GPs in Denmark only get a small regular income per patient registered with the GP and are mainly paid by the services performed. CNs, on the other hand, have a set income and received no compensation for participation. GP non-responders were sent reminders four and seven weeks following the first questionnaire.

The 65-item questionnaire to relatives was pilot-tested among 14 bereaved relatives not included in this study. Non-responders of relatives were sent one reminder four weeks after the first questionnaire. From the relatives we obtained data on their age $(18-65,66+)$, gender, relation to the deceased (non-spouse, spouse), whether they were living with the patient (no, yes) and their own vocational educational level ( 3 years or less, $>3$ years). Furthermore, to examine 'A successful palliative pathway at home' the relatives were asked to evaluate the palliative pathway, answering the following question: 'How, in your own words, was the entire period at home during which the deceased was dying compared with how you felt it should have been?' (dichotomized into unsuccessful ('Fairly well', 'Bad', 'Very bad') and successful ('Very well', 'Well')).

We retrieved register data on patient age $(18-65,66+)$, gender, cancer diagnosis (lung, colo-rectal, breast, pros- 
tate, other) and place of death (institution (hospital and hospice), nursing home, home and other).

\section{Analysis}

'A successful palliative pathway at home' as defined by the bereaved relative was used as the outcome measure and we calculated associations with 1) place of death and 2) nurse involvement. The multivariate model consisted of the variables seen in Table 2 plus the duration of the palliative period spent at home (number of weeks as a categorical variable), since it could be associated with the CNs' possibility to provide palliative care.

Unadjusted and adjusted associations were calculated. Using robust variance estimates, the estimates were adjusted for clustering of patients seen by the same $\mathrm{CN}$ [14]. Prevalence ratios (PRs) with 95\% confidence intervals (95\% CIs) were used as a measure of association. Due to the high prevalence of the outcome measure (more than $20 \%$ 'successful palliative pathways at home'), odds ratios would overestimate the association $[15,16]$. PRs were calculated with generalised linear models (GLM) with log link and the Bernoulli family, and when the model did not converge, we used the Poisson regression model $[15,17]$.

The variables were assessed for collinearity (Pearson's correlation coefficient $>0.4$ ) and multicollinearity (variance inflation factor < 10) $[18,19]$. Due to collinearity, 'Relatives living with the patient' and 'CNs' age' were not included in the multivariate model. Neither forward nor backward selection was performed. Data were analyzed using STATA 10 [20].

\section{Ethics}

According to Scientific Committee for the County of Aarhus, the Biomedical Research Ethics Committee System Act does not apply here. The study was approved by the Danish Data Protection Agency and the Danish National Board of Health.

\section{Results}

A total of 201 questionnaires from $129 \mathrm{CNs}$ were obtained. For 178 cases, the CN or GP stated that there had been no home care during the palliative pathway or that the patient had been a nursing home resident from the beginning of the palliative pathway and therefore had had no contact with CNs. The remaining cases all had a palliative period at home no matter where they eventually died. For 220 cases the nurse did not respond, leaving a response rate of $47.7 \%$ (Figure 2). The 220 cases from non-responding $\mathrm{CNs}$ were not statistically significantly different from the included cases in terms of patient gender and number of GP home-visits, but the non-responder cases tended to be significantly older and to die more often at a nursing home (Table 3 ).

For 52 cases ( $25.9 \%$ of the 201 cases with nurse response), the $\mathrm{CN}$ or GP advised against sending the relative a questionnaire (Figure 2). A total of 101 relative questionnaires were obtained and two were excluded since the relative stated that the questionnaire was not relevant to the pathway at all, leaving 46 relatives as non-responders (response rate 68.7\%) (Figure 2).

Comparison of the 101 included cases with the 46 cases where the relatives did not respond showed that relatives answered the questionnaire significantly more frequently when the questionnaire concerned a male patient ( $\mathrm{p}$ value $<0.05)$ than when it concerned a female patient (Table 4).

Comparing the 101 included cases with the 52 cases where CNs or GPs advised against sending the relative a questionnaire showed that cases included comprised more home-deaths, less institutional and nursing-homedeaths and were characterised by the CNs having more contact to the relatives ( $\mathrm{p}$-value $<0.05)$ (Table 4).

\section{Associations with evaluation of palliative pathway at home}

'A successful palliative pathway at home' was statistically significantly associated with home-death (2.3 (95\% CI: $1.2 ; 4.4)$ ) (Table 2). It was also associated with nursing home-death compared with hospital-death $(1.8$ (95\% CI: $0.9 ; 3.7)$, even if the association fell short of significance. None of the variables concerning $\mathrm{CN}$ involvement were statistically significantly associated with a successful palliative pathway at home.

\section{Discussion \\ Main findings}

In a group of patients who died from cancer and had a palliative pathway at home, we found that the relatives' positive evaluation of the palliative pathway at home was associated with home-death and nursing-home-death. However, the latter association was not significant. Surprisingly, we identified no significant associations between the evaluations and the involvement of CNs.

\section{Strengths and limitations of the study}

The strengths of this study are its sampling and its comprehensive data collection. To eliminate differential misclassification, we used the standardised official health registers to identify the study population, including the places and the reasons of death. To minimise recall bias, the questionnaire was sent in January 2007. Thus, we did not await the update of the Danish Register of Causes of Death in 2008. 
Table 2: Associations between a successful palliative pathway at home and model variables.

\begin{tabular}{|c|c|c|}
\hline & $\begin{array}{l}\text { Unadjusted prevalence ratio } \\
(95 \% \mathrm{Cl})\end{array}$ & $\begin{array}{l}\text { Adjusted prevalence ratio } \\
(95 \% \mathrm{Cl})\end{array}$ \\
\hline $\begin{array}{l}\text { Gender of relative } \\
\text { Male } \\
\text { Female }\end{array}$ & $\begin{array}{c}\mathrm{I} \\
1.0(0.8 ; 1.4)\end{array}$ & $\stackrel{1}{1}$ \\
\hline $\begin{array}{l}\text { Age of relative } \\
\quad 18-64 \\
65+\end{array}$ & $\begin{array}{l}1 \\
1.3(1.0 ; 1.7)\end{array}$ & $\begin{array}{c}\mathrm{I} \\
1.0(0.8 ; 1.6)\end{array}$ \\
\hline $\begin{array}{l}\text { Living with patient } \\
\text { No } \\
\text { Yes }\end{array}$ & $\stackrel{1}{1}$ & $\begin{array}{l}\text { Not included because of collinarity with } \\
\text { 'Relatives' relation to deceased' }\end{array}$ \\
\hline $\begin{array}{l}\text { Relative's relation to diseased } \\
\text { Not spouse } \\
\text { Spouse }\end{array}$ & $\stackrel{1}{1}$ & $\stackrel{1}{1}$ \\
\hline $\begin{array}{l}\text { Relative's vocational education } \\
3 \text { years or less } \\
>3 \text { years }\end{array}$ & $0.8(0.6 ; 1.1)$ & $\begin{array}{c}1 \\
0.7(0.3 ; 1.3)\end{array}$ \\
\hline $\begin{array}{l}\text { CN's age } \\
\text { Less than } 40 \\
40 \text { and above }\end{array}$ & $\stackrel{1}{1}$ & $\begin{array}{c}\text { Not included because of collinarity with } \\
\text { 'CN's years as CN' }\end{array}$ \\
\hline $\begin{array}{l}\text { CN's years as } \mathbf{C N} \\
\text { Five and less } \\
\text { More than five }\end{array}$ & $1.2(0.9 ; 1.5)$ & $0.9(0.6 ; 1.3)$ \\
\hline $\begin{array}{l}\text { CN's extra education or courses } \\
\text { No } \\
\text { Yes }\end{array}$ & 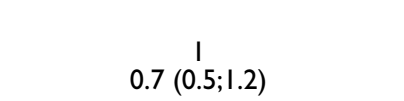 & $\stackrel{1}{1}$ \\
\hline $\begin{array}{l}\text { CN's knowledge prior to palliati } \\
\text { Poor } \\
\text { Well }\end{array}$ & $\stackrel{1}{1}$ & $\stackrel{1}{1}$ \\
\hline $\begin{array}{l}\text { CN's contact with relatives } \\
\text { No } \\
\text { Yes }\end{array}$ & $\stackrel{1}{\mathrm{I}} 0.6(0.6 ; 0.7)$ & $\stackrel{1}{1}$ \\
\hline $\begin{array}{l}\text { CN's and community services' } \mathbf{h} \\
\text { Less than one } \\
\text { One or more }\end{array}$ & $\begin{array}{l}\mathrm{I} \\
0.9(0.6 ; 1.2)\end{array}$ & $0.7(0.4 ; 1.1)$ \\
\hline $\begin{array}{l}\text { GP involvement } \\
\text { No } \\
\text { Yes }\end{array}$ & $\begin{array}{c}1 \\
1.0 \\
(0.7 ; 1.3)\end{array}$ & $\stackrel{1}{1}$ \\
\hline $\begin{array}{l}\text { Specialist team involvement } \\
\text { No } \\
\text { Yes }\end{array}$ & $\stackrel{1}{1}$ & $\stackrel{1}{1}$ \\
\hline $\begin{array}{l}\text { Place of death } \\
\text { Institution (Hospital or Hospice) } \\
\text { Nursing home } \\
\text { Home }\end{array}$ & $\begin{array}{l}1 \\
1.3(0.7 ; 2.5) \\
1.7(1.1 ; 2.7)\end{array}$ & $\begin{array}{c}1 \\
1.8(0.9 ; 3.7) \\
2.3(1.2 ; 4.4)\end{array}$ \\
\hline
\end{tabular}

A total of $10 \mathrm{I}$ cases were included in the analyses. The unadjusted and the adjusted prevalence ratios (PRs) are shown with $95 \%$ confidence intervals $(95 \% \mathrm{Cls})$. CN is the Community nurse involved. 
The major weakness of these analyses was the selection bias. We found differences between included cases and the cases where the relatives had been excluded by $\mathrm{CNs}$ or GPs. The differences meant that we would tend to exclude those cases where the $\mathrm{CN}$ was not as involved and did not know the patient as well as in those cases that were included. In these excluded cases, the relative may evaluate the pathway as less successful or tend to see the nurses' involvement as less important. Thus, we would tend to overestimate the associations between a successful pathway at home and CN-related variables. This would also be the case if the CNs or the GPs had excluded cases that they knew had been unsuccessful (which they might have cho- sen to do for a number of reasons) despite $\mathrm{CN}$ involvement. As home-death is associated with $\mathrm{CN}$ involvement [8-10], such selection bias, therefore, tends to strengthen the association between home-death and a successful pathway at home. Furthermore, it is seen from Table 4 that more relatives of male than of female patients answered the questionnaires compared to the nonresponding group. However, there is no evidence that the patient's sex is associated with the relatives' satisfaction of end-of-life care [21].

Our results are generalizable to patients who receive palliative home-care in a healthcare system similar to the Dan-

Table 3: Characteristics of $20 \mathrm{I}$ included cases and 220 cases not included because the community nurses (CNs) did not respond.

\begin{tabular}{|c|c|c|}
\hline & $\begin{array}{l}\text { Cases of community nurse responders } \\
\text { ( } N=201,129 \text { nurses })\end{array}$ & $\begin{array}{l}\text { Cases of Community nurse non- } \\
\text { responders } \\
(\mathbf{N}=220)\end{array}$ \\
\hline CN's gender (n (\%)) & & - \\
\hline Male & $0(0.0)$ & \\
\hline Female & $129(100.0)$ & \\
\hline CN's age (Mean $(95 \% \mathrm{Cl}))$ & $45.3(43.9 ; 46.7)$ & - \\
\hline Years as nurse (Mean $(95 \% \mathrm{Cl})$ ) & $19.9(18.2 ; 21.5)$ & - \\
\hline Years as CN (Mean $(95 \% \mathrm{Cl}))$ & $10.7(9.5 ; 12.0)$ & - \\
\hline $\begin{array}{l}\text { Number of questionnaires pr CN (Median } \\
(\text { IQI)) }\end{array}$ & $1.4(1.3 ; 1.5)$ & - \\
\hline $\begin{array}{l}\text { CN's extra education or courses in } \\
\text { palliative care }(\mathrm{n}(\%))\end{array}$ & & - \\
\hline No & $107(84.9)$ & \\
\hline Yes & $19(15.1)$ & \\
\hline $\begin{array}{l}\text { Patient's age at time of death (mean }(95 \% \\
\mathrm{Cl}))^{*}\end{array}$ & $70.0(68.4 ; 71.6)$ & $72.8(71.0 ; 74.5)$ \\
\hline \multicolumn{3}{|l|}{ Patient's gender (n (\%)) } \\
\hline Male & III (55.2) & $129(58.4)$ \\
\hline Female & $90(44.8)$ & $91(41.6)$ \\
\hline \multicolumn{3}{|l|}{ Primary cancer diagnosis (n (\%)) } \\
\hline Bronchus/lung & $34(16.9)$ & $48(21.8)$ \\
\hline Colon/rectum & $26(12.9)$ & $39(17.7)$ \\
\hline Breast & $23(11.4)$ & $20(9.1)$ \\
\hline Prostate & $31(15.4)$ & $26(11.8)$ \\
\hline Other & $87(43.4)$ & $87(39.6)$ \\
\hline \multicolumn{3}{|l|}{ Place of death $(\mathrm{n}(\%))^{*}$} \\
\hline Home & $97(48.3)$ & $79(35.9)$ \\
\hline Nursing home & $35(17.4)$ & $59(26.8)$ \\
\hline Hospital/hospice & $67(33.3)$ & $82(35.9)$ \\
\hline Other (e.g. other institution) & $2(1.0)$ & $3(1.4)$ \\
\hline
\end{tabular}

* Statistically significantly different from 101 cases included in study with p-value $<0.05$

Data on nurses obtained from $\mathrm{CN}$ questionnaires. Case data are obtained from formal health registers. 


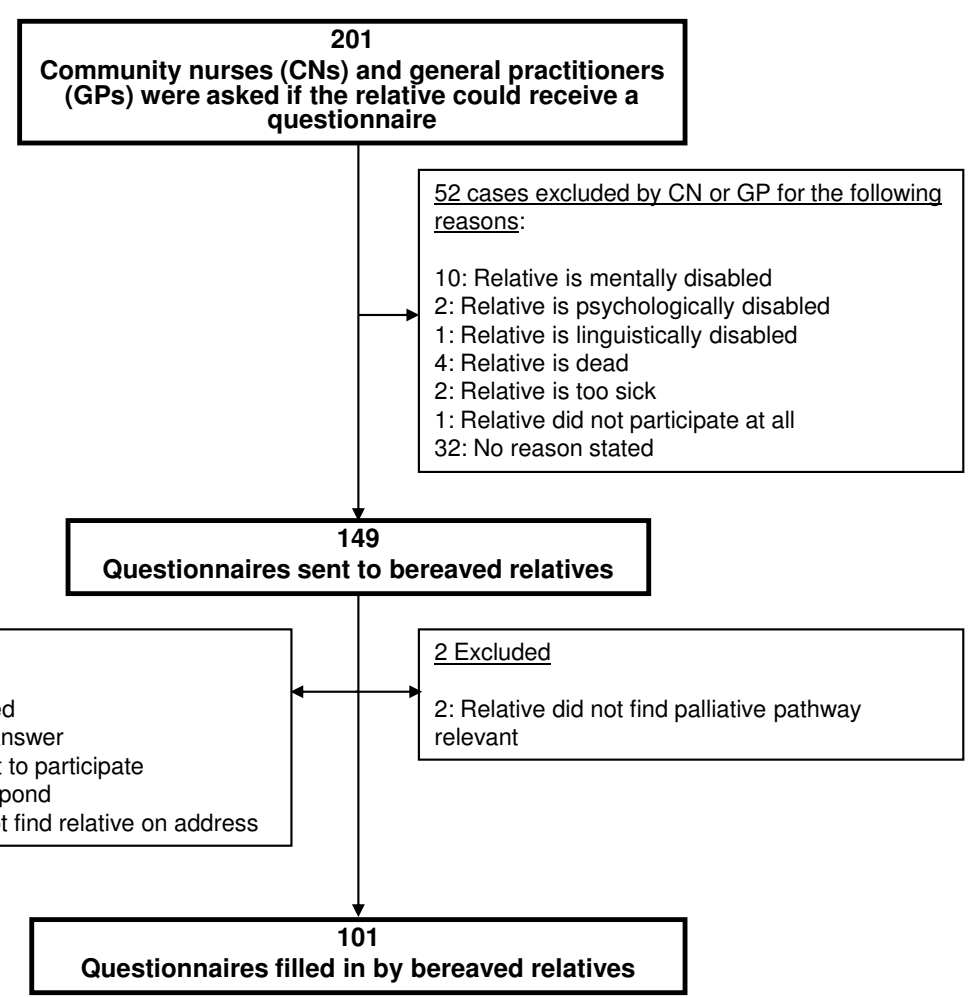

Figure 2

Flow-chart of questionnaires to bereaved relatives. Responders and non-responders.

ish system because we sampled patients who died from cancer and had some palliative period at home, regardless of the involvement of specialised teams or hospital records and because Denmark is quite homogenous with respect to primary care and social demography.

Approximately 1680 patients died from cancer in Aarhus County in 2006, and we included 599 cases recruited during a nine-month period (Figure 1). The discrepancy between the total number of deaths and the number of cases included may appear because we did not include persons less than 18 years, non-melanoma cancer cases, and because we included only those with a cancer diagnosis registered in a hospital in Aarhus County as their main diagnose of admittance within a 10 -year period. Furthermore, the period where patients could die $\left(1^{\text {st }}\right.$ March-30 $3{ }^{\text {th }}$ November) did not include the winter months of 2006, which may imply that some cases were missing, since winter months may have a higher average of deaths than the rest of the year.

\section{Discussion of results and comparison with existing literature}

We found that home-death was statistically significantly associated with the relatives' evaluation of the palliative pathway at home as being more successful compared with pathways ending with institutional death. In line with this, previous studies have shown that home-death was associated with better bereavement response [22-24] and overall satisfaction with the palliative pathway at home [21]. The fact that a successful palliative pathway at home is associated with home-death is hardly surprising. Most studies show that most terminally ill patients and their relatives wish death to take place at home [3,25-27] and an institutional death may be a direct consequence of a poor palliative pathway at home. However, one may also argue that in the last days of life, being at home may be distressing for the relatives, and an institutional death may be preferred even if the palliative pathway at home has, indeed, been successful. It may even make the pathway at home look even more successful in retrospect since the distressing and care-demanding last days of the patient's life did not take place at home. In this context, the found association is more interesting.

The association between a successful pathway at home and home-death in this study may also be partly rooted in the fact that patients dying at a hospital or hospice often have worse symptoms and problems, e.g. pain, than patients dying at home, which, indeed, would affect the 
Table 4: Characteristics of $10 \mathrm{I}$ included cases, the 46 cases not included because the relative did not respond and the 52 cases where the general practitioners (GP) or the community nurse (CN) advised against sending the relative a questionnaire.

\begin{tabular}{|c|c|c|c|}
\hline & $\begin{array}{l}\text { Cases in study } \\
(\mathrm{N}=101)\end{array}$ & $\begin{array}{l}\text { Cases of relative-non-responders } \\
\qquad(N=46)\end{array}$ & $\begin{array}{c}\text { Cases where the GP or } \mathrm{CN} \text { advised } \\
\text { against sending the relative a } \\
\text { questionnaire } \\
(\mathbf{N}=52)\end{array}$ \\
\hline $\begin{array}{l}\text { Patient's age at time of death } \\
(\text { mean }(95 \% \mathrm{Cl}))\end{array}$ & $69.6(67.3 ; 71.9)$ & $68.1(64.8 ; 71.4)$ & $73.0(69.9 ; 76.2)$ \\
\hline \multicolumn{4}{|l|}{ Patient's gender (n (\%)) } \\
\hline Male & $61(60.4)$ & $18(39.1)^{*}$ & $30(57.7)$ \\
\hline Female & $40(39.6)$ & $28(60.9)^{*}$ & $22(42.3)$ \\
\hline \multicolumn{4}{|l|}{ Primary cancer diagnosis ( $(\%)$ ) } \\
\hline Bronchus/lung & $16(15.8)$ & $10(21.7)$ & $8(15.4)$ \\
\hline Colon/Rectum & $13(12.9)$ & $8(17.4)$ & $5(9.6)$ \\
\hline Breast & II (10.9) & $9(19.6)$ & $3(5.8)$ \\
\hline Prostate & $17(16.8)$ & $3(6.5)$ & $\mathrm{II}(2 \mathrm{I} .2)$ \\
\hline Other & $44(43.6)$ & $16(34.8)$ & $25(48.1)$ \\
\hline \multicolumn{4}{|l|}{ Place of death (n (\%)) } \\
\hline Home & $62(6 \mid .4)$ & $25(54.4)$ & $10(19.2)^{*}$ \\
\hline Nursing home & $13(12.9)$ & $3(6.5)$ & $18(34.6)^{*}$ \\
\hline Hospital/Hospice & $25(24.8)$ & $18(39.1)$ & $23(44.2)^{*}$ \\
\hline Other (e.g. other institution) & I (I.0) & $0(0.0)$ & I (1.9) \\
\hline $\begin{array}{l}\text { Relative's age at time of filling in } \\
\text { questionnaire }\end{array}$ & & - & - \\
\hline$($ mean $(95 \% \mathrm{Cl}))$ & $58.3(55.4 ; 61.2)$ & & \\
\hline Gender of relative (n (\%)) & & - & - \\
\hline Male & $28(27.7)$ & & \\
\hline Female & $73(72.3)$ & & \\
\hline $\begin{array}{l}\text { Relative's relation to deceased ( } \mathrm{n} \\
(\%))\end{array}$ & & - & - \\
\hline Spouse & $63(62.4)$ & & \\
\hline Girlfriend or boyfriend & $I(1.0)$ & & \\
\hline Daughter or son & $32(31.7)$ & & \\
\hline Sister or brother & I (I.0) & & \\
\hline Parent & $\mathrm{I}(\mathrm{I} .0)$ & & \\
\hline Daughter-in-law & $3(3.0)$ & & \\
\hline Relative lived with patient (n (\%)) & & - & - \\
\hline No & $23(23.7)$ & & \\
\hline Yes & $74(76.3)$ & & \\
\hline $\begin{array}{l}\text { Relative's vocational education ( } \mathrm{n} \\
(\%))\end{array}$ & & - & - \\
\hline 3 years or less & $62(63.3)$ & & \\
\hline$>3$ years & $36(36.7)$ & & \\
\hline CN's age (mean $(95 \% \mathrm{Cl})$ & $44.4(42.7 ; 46.2)$ & $46.2(43.8 ; 48.6)$ & $46.1(43.9 ; 48.4)$ \\
\hline \multicolumn{4}{|l|}{ CN's years as CN (n (\%)) } \\
\hline Five and less & $36(40.0)$ & $16(40.0)$ & $12(25.0)$ \\
\hline More than five & $54(60.0)$ & $24(60.0)$ & $36(75.0)$ \\
\hline
\end{tabular}

CN's extra education or courses in palliative care $(\mathrm{n}(\%))$ 
Table 4: Characteristics of $10 \mathrm{I}$ included cases, the 46 cases not included because the relative did not respond and the 52 cases where the general practitioners (GP) or the community nurse (CN) advised against sending the relative a questionnaire. (Continued)

\begin{tabular}{|c|c|c|c|}
\hline \multicolumn{4}{|l|}{ No } \\
\hline \multirow[t]{2}{*}{ Yes } & $70(82.4)$ & $34(85.0)$ & $39(86.7)$ \\
\hline & $15(17.6)$ & $6(15.0)$ & $6(13.3)$ \\
\hline \multicolumn{4}{|c|}{$\begin{array}{l}\text { CN's and community services' } \\
\text { home-visits pr day (n (\%)) }\end{array}$} \\
\hline \multicolumn{4}{|l|}{ Less than one } \\
\hline \multirow[t]{2}{*}{ One or more } & $14(14.7)$ & $5(12.2)$ & $9(18.4)$ \\
\hline & $81(85.3)$ & $36(87.8)$ & $40(81.6)$ \\
\hline \multicolumn{4}{|c|}{$\begin{array}{l}\text { CN's knowledge prior to palliative } \\
\text { period }(\mathrm{n}(\%))\end{array}$} \\
\hline \multicolumn{4}{|l|}{ Poor } \\
\hline \multirow[t]{2}{*}{ Well } & $57(60.6)$ & $22(51.2)$ & $29(56.9)$ \\
\hline & $37(39.4)$ & $21(48.8)$ & $22(43.1)$ \\
\hline \multicolumn{4}{|c|}{ CN's contact with relatives $(\mathrm{n}(\%))$} \\
\hline No & $3(3.1)$ & $2(4.7)$ & $15(30.6)^{*}$ \\
\hline Yes & $94(96.9)$ & $4 I(95.3)$ & $34(69.4) *$ \\
\hline \multicolumn{4}{|c|}{ GP involvement ( $\mathrm{n}(\%)$ ) } \\
\hline No & $14(15.2)$ & $4(9.3)$ & $10(20.0)$ \\
\hline Yes & $78(84.8)$ & $39(90.7)$ & $40(80.0)$ \\
\hline \multicolumn{4}{|c|}{ Specialist team involvement ( $\mathrm{n}(\%)$ ) } \\
\hline No & $39(55.7)$ & $21(58.3)$ & $21(56.8)$ \\
\hline Yes & $31(44.3)$ & $15(41.7)$ & $16(43.2)$ \\
\hline
\end{tabular}

* Statistically significantly different from the 101 cases in study with p-value $<0.05$.

Not all sums of percentages are added to $100.0 \%$ because of round-offs.

Case data in study stem from GP, CN and relative-questionnaires and from formal health registers. Case data of relative-non-responders and of the group where the GP advised against sending the relative a questionnaire stem from GP and CN questionnaires and formal health registers.

relatives' evaluation. We included no variables that could describe symptom and problem severity since the included variables were identified through literature studies, clinical experience and group interview studies with bereaved relatives [5] and involved professionals (CNs, GPs and hospital consultants), and this issue did not come up. However, patients with severe symptoms may also have more contact with a palliative specialist team, and if we had adjusted for this we might have reduced some confounding. However, eliminating 'specialist team involvement' from the model would weaken the association between a successful pathway at home and homedeath, but only slightly, which indicates that symptoms may be a confounder for which control was not fully achieved.

We also found that dying at a nursing home was associated with the relatives' evaluation of the palliative pathway at home compared with institutional death. But this association fell short of statistical significance in our study with only 101 included cases. A reason for this result could, again, be that patients dying at a hospital or hospice presumably have worse symptoms than those who die at home and at nursing homes. Further research is needed to investigate the implications of death at home and at nursing homes for patients and relatives.

Quality in dying is much debated and there is no doubt that what makes a good death is determined by a complex interplay of many factors, e.g. personal and cultural values, supportive network characteristics, physical and medical factors, and the services offered by the health care systems. Surprisingly, we found that none of the $\mathrm{CN}$ related factors in our model were statistically significantly associated with the relatives' evaluation of the palliative pathway at home. To our knowledge, no previous studies have explored the association between relatives' or patients' evaluation of the palliative pathway at home and $\mathrm{CN}$-related factors. However, studies show that the following factors are positively associated with bereaved relatives' satisfaction with the $\mathrm{CN}$ during the palliative pathway: frequent $\mathrm{CN}$ home-visits, visiting at night, knowing enough and spending enough time in the homes[28,29]. The lack of significance of CNs' involvement may be due to the involvement variables chosen in this study, or maybe the CNs' effect on the pathway at 
home may be like a package, where it is more a question of the existence of a $\mathrm{CN}$-service in the home or not.

It is striking that we observed no association with the included variables in the model, except for the place of death. This may be due to the small size of the study and the amount of variables included, but it may also be due to the fact that other kinds of factors are pivotal to relatives in achieving a good palliative pathway at home, i.e. the relation between the patient and the relative; the backup provided by other relatives and colleagues; patient factors; and factors relating to practical arrangements in the home, etc. This, again, calls for more research in the field.

\section{Implications for future research}

More research is needed on how to measure bereaved relatives' evaluation of palliative pathways, how the factors concerning CNs' involvement are affecting this evaluation and what constitutes a well-performed palliative effort by the CNs. Furthermore, studies of the predictive power of a more active approach in primary health services in achieving a successful palliative pathway are needed.

\section{Conclusion}

Our study indicates that dying at home is positively associated with an increase in the likelihood that the bereaved relative will evaluate the palliative pathway at home as successful. Symptom severity may be an important confounder; one that was not adjusted for in the present study. No significant associations between the evaluations and way the CNs were involved could be identified. There is a need for studies exploring predictors of the primary care effort associated with a "good death" to improve and ensure more focus in the palliative primary health care effort.

\section{Competing interests}

The authors declare that they have no competing interests.

\section{Authors' contributions}

MAN participated in the design of the study, in the development of the questionnaires, handled the data, drafted the manuscript and performed the statistical analysis.

PV helped to draft the manuscript and IS helped to perform the statistical analysis

$\mathrm{FO}, \mathrm{ABJ}$ and JS participated in the design of the study and in the development of the questionnaires. JS also helped to draft the manuscript.

All authors read and approved the final manuscript.

\section{Acknowledgements}

Profound gratitude is extended to participating bereaved relatives, CNs and GPs. The study was funded by the Aarhus County Research Fund for the
Clinical Development and Research in General Practice and across the Primary and Secondary Health Care Sectors (4-0I-3-04), the Danish National Research Foundation for Primary Care (585-457808) and The Multipractice Study Committee (585-04/2072).

\section{References}

I. Higginson IJ, Sen-Gupta GJ: Place of care in advanced cancer: a qualitative systematic literature review of patient preferences. J Palliat Med 2000, 3:287-300.

2. Tang ST: When death is imminent: where terminally ill patients with cancer prefer to die and why. Cancer Nurs 2003, 26:245-25I.

3. Thomas C, Morris SM, Clark D: Place of death: preferences among cancer patients and their carers. Soc Sci Med 2004, 58:243I-2444.

4. Neergaard MA, Vedsted P, Olesen F, Sokolowski I, Jensen AB, Sondergaard J: Associations between home-death and general practitioner involvement in palliative cancer care. $\mathrm{Br} J \mathrm{Gen}$ Pract 2009, 59:67I-677.

5. Neergaard MA, Olesen F, Jensen AB, Sondergaard J: Palliative care for cancer patients in a primary health care setting: Bereaved relatives' experience, a qualitative group interview study. BMC Palliat Care 2008, 7:I.

6. Weibull $A$, Olesen $F$, Neergaard MA: Caregivers' active role in palliative home care - to encourage or to dissuade? A qualitative descriptive study. BMC Palliat Care 2008, 7:I5.

7. Brazil K, Bedard M, Krueger P, Abernathy T, Lohfeld L, Willison K: Service preferences among family caregivers of the terminally ill. J Palliat Med 2005, 8:69-78.

8. Aabom B, Kragstrup J, Vondeling H, Bakketeig LS, Stovring H: Population-based study of place of death of patients with cancer: implications for GPs. Br J Gen Pract 2005, 55:684-689.

9. Fukui S, Fukui N, Kawagoe H: Predictors of place of death for Japanese patients with advanced-stage malignant disease in home care settings: a nationwide survey. Cancer 2004, 10 1:42 1-429.

10. Howat $A$, Veitch $C$, Cairns $W$ : A retrospective review of place of death of palliative care patients in regional north Queensland. Palliat Med 2007, 21 :4 I-47.

II. The Danish National Board of Health: The Danish Register of Causes of Death [In Danish] 2008.

12. Pedersen CB, Gotzsche H, Moller JO, Mortensen PB: The Danish Civil Registration System. A cohort of eight million persons. Dan Med Bull 2006, 53:44I-449.

13. Neergaard MA: Palliative home care for cancer patients in Denmark - with a particular focus on the primary care sector, GP's and community nurses. PhD Thesis 2009 [http://www.dadlnet.dk/app/plsql/ dmb phd.phd?v phd=I59I]. Faculty of Health Sciences, Aarhus University. Research Unit and Department of General Practice

14. Donner A, Klar N: Design and Analysis of Cluster Randomisation Trials in Health Research Ist edition. London: Hodder Arnold; 2000.

15. Barros AJ, Hirakata VN: Alternatives for logistic regression in cross-sectional studies: an empirical comparison of models that directly estimate the prevalence ratio. BMC Med Res Methodol 2003, 3:21.

16. Thompson ML, Myers JE, Kriebel D: Prevalence odds ratio or prevalence ratio in the analysis of cross sectional data: what is to be done? Occup Environ Med 1998, 55:272-277.

17. Zou G: A modified poisson regression approach to prospective studies with binary data. Am J Epidemiol 2004, I 59:702-706.

18. Armitage P, Berry G, Matthews JNS: Statistical Methods in Medical Research 4th edition. Oxford: Blackwell Science; 2005.

19. O'Brien RM: A Caution Regarding Rules of Thumb for Variance Inflation Factors. Quality and Quantity 2007, 41:673-690.

20. Stata Statistical Software: Release 9.0 College Station, TX: StataCorp LP; 2005.

21. Ringdal GI, Jordhoy MS, Kaasa S: Family satisfaction with end-oflife care for cancer patients in a cluster randomized trial. J Pain Symptom Manage 2002, 24:53-63.

22. Grande GE, Farquhar MC, Barclay SI, Todd CJ: Caregiver bereavement outcome: relationship with hospice at home, satisfaction with care, and home death. J Palliat Care 2004, 20:69-77.

23. Akiyama A, Numata K, Mikami H: Factors enabling home death of the elderly in an institution specializing in home medical 
care: analysis of apprehension of the bereaved family. Geriatr Gerontol Int 2008, 8:73-79.

24. Heide A van der, de Vogel-Voogt E, Visser AP, Rijt CC van der, Maas PJ van der: Dying at home or in an institution: perspectives of Dutch physicians and bereaved relatives. Support Care Cancer 2007, I 5: | 413-142|.

25. Hanratty B: Palliative care provided by GPs: the carer's viewpoint. Br J Gen Pract 2000, 50:653-654.

26. Thomas C: The place of death of cancer patients: can qualitative data add to known factors? Soc Sci Med 2005, 60:2597-2607.

27. Grande GE, Farquhar MC, Barclay SI, Todd CJ: Valued aspects of primary palliative care: content analysis of bereaved carers' descriptions. Br J Gen Pract 2004, 54:772-778.

28. Fakhoury W, McCarthy M, Addington-Hall J: Determinants of informal caregivers' satisfaction with services for dying cancer patients. Soc Sci Med 1996, 42:72I-73I.

29. Lecouturier J, Jacoby A, Bradshaw C, Lovel T, Eccles M: Lay carers' satisfaction with community palliative care: results of a postal survey. South Tyneside MAAG Palliative Care Study Group. Palliat Med 1999, 13:275-283.

\section{Pre-publication history}

The pre-publication history for this paper can be accessed here:

http://www.biomedcentral.com/1472-684X/8/18/pre

pub

Publish with Bio Med Central and every scientist can read your work free of charge

"BioMed Central will be the most significant development for disseminating the results of biomedical research in our lifetime."

Sir Paul Nurse, Cancer Research UK

Your research papers will be:

- available free of charge to the entire biomedical community

- peer reviewed and published immediately upon acceptance

- cited in PubMed and archived on PubMed Central

- yours - you keep the copyright

Submit your manuscript here:

http://www.biomedcentral.com/info/publishing_adv.asp
BioMedcentral 